\title{
The positive reinforcing efficacy of a discriminative stimulus established under aversive conditions'
}

\author{
W. W. WENRICH, ROANOKE COLLEGE,
}

\section{D. CAHOON, AUBURN UNIVERSITY}

R. H. MOHER, ROANOKE COLLEGE

\begin{abstract}
Studies of discriminative stimuli as conditioned reinforcers have typically considered $\mathrm{S}^{\mathrm{D}_{\mathrm{S}}}$ established in appetitive situations. In this project additional evidence is offered that $\mathrm{SD}_{\mathrm{S}}$ established under circumstances in which reinforcement stems from the removal of negatively reinforcing stimuli (the aversive situation) also have reinforcing efficacy.
\end{abstract}

\section{Introduction}

It is generally accepted that discriminative stimuli function also as conditioned reinforcers. The most convincing empirical support for this assertion, however, has derived from demonstrations in which the $\mathrm{SD}_{\mathrm{S}}$ had set the occasion for responses followed by positive reinforcement. That stimuli discriminative for operants which remove noxious stimulation are also reinforcing has been less well demonstrated, although a few recent reports have been suggestive (e.g. Dinsmoor \& Clayton, 1963; Wenrich \& Cahoon, 1965). The present investigation was designed to provide additional evidence relative to the question of whether stimuli related to a discriminated response that had terminated negative reinforcement, i.e., $\mathrm{SD}_{\mathrm{S}}$ established in an aversive situation, function as conditioned reinforcers.

\section{Subjects}

Four experimentally naive male albino rats, 60-70 days old at the initiation of the study, were used.

\section{Apparatus}

A standard Foringer Skinner box and associated electronic devices including programming clocks, relays, and counters were employed, and a Foringer 1925 grid shock scrambler.

Procedure

The basic experimental procedure extended through 16 days. The Ss were placed in the Skinner box for 30 min. the initial day to allow for adaptation. The bar was not present, and a light and the sound of a clicker were presented for $3 \mathrm{sec}$. each $15 \mathrm{sec}$. of this interval. During the second day an effort was made to determine if the light and clicker were reinforcing stimuli prior to discrimination training. It was abundantly clear that they were not, and, indeed, their presentation appeared to be related to a slight decrease in response rate. On days 3 and 4 the bar-pressing operant was conditioned with the presentation of food pellets $(45 \mathrm{mg}$ Noyes pellets) as the reinforcing stimulus. The following day (day 5), each $\mathrm{S}$ was run for $20 \mathrm{~min}$. under a mild (3.2 milliamperes; 240 volts) condition. The shock was presented continuously except when terminated for 15 sec. by each bar-pressing response.
During this phase food pellets were not employed as contingent stimuli. The light and clicker were made discriminative for the bar press in the aversive situation on the sixth day. That is, when the light and clicker were present, a response terminated the shock for 15 sec.; when the light and clicker were not present, the bar press did not result in shock termination. The Ss were run under these conditions for $20 \mathrm{~min}_{\circ}$, and the light and clicker were presented and withdrawn during alternating $30-\mathrm{sec}$. intervals. The next five days (days 7-11) were similar to day 6 except that $\mathrm{S}{ }^{\Delta}$ was now set at $20 \mathrm{sec}$. If $\mathrm{S}$ responded during the $\mathrm{S} \Delta_{\text {interval, the interval was reset. That is, the light }}$ and clicker were presented only after a continuous 20 -sec. period in which no bar press responses were emitted.

Following the completion of this phase the Ss were not exposed to shock stimuli during the remainder of the experiment. During days 12-15 the rats, who at this point had been reduced to $80 \%$ of their ad lib weight, were again reinforced by food pellets. The light and clicker were not presented and S was left in the box each day until he had emitted a total of 50 bar-press responses.

Day 16 was the "test day." The two rats preselected as experimental Ss ( $\mathrm{S}_{3}$ and $\mathrm{S}_{4}$ ) were placed in the Skinner box and allowed to press the bar for $10 \mathrm{~min}$. during which the only contingent stimulus was the sound of the food magazine. Immediately following this period was a 5-min. interval in which each response was followed by the light and clicker for 1 sec., as well as by the sound of the food magazine. For the control Ss $\left(\mathrm{S}_{1}\right.$ and $\left.\mathrm{S}_{2}\right)$ a bar press was followed only by the sound of the food magazine for the entire 15-min.test period.

\section{Results and Discussion}

The comparative number of responses emitted by the experimental and control Ss is summarized in Table 1 .

It is highly probable that the light and clicker function as secondary positive reinforcers. During the final 5-min. interval, in which the light and clicker are presented as contingent stimuli to $S_{3}$ and $S_{4}$, the response rate of these experimental Ss is more than 10 times as great as that of the control Ss $\left(\mathrm{S}_{1}\right.$ and $\left.\mathrm{S}_{2}\right)$.

Additional evidence relative to the reinforcing efficacy of the discriminative stimuli was provided by further efforts with one of the control Ss (S1). Following reconditioning using food pellets, the rat's responses were once again followed only by the sound of the food 
TABLE I

Number of Bar Press Responses Emitted during Three Successive 5-min. Periods. While all Ss have received discrimination training in an aversive situation only $S_{3}$ and $S_{4}$ are presented with the $\mathbf{S}^{\mathbf{S}}$ from that situation (a light and clicker), during the final 5-min. period

\begin{tabular}{|c|c|c|c|}
\hline $\mathrm{S}$ & INTERVAL 1 & $\begin{array}{l}\text { RESPONSES } \\
\text { INTERVAL } 2\end{array}$ & INTERVAL 3 \\
\hline 1 & 40 & 13 & 10 \\
\hline 2 & 55 & 25 & 4 \\
\hline 3 & 40 & 28 & 81 \\
\hline 4 & 63 & 18 & 73 \\
\hline \multirow[t]{2}{*}{ Tot } & $\times 295$ & 38 & 14 \\
\hline & 3. 4103 & 46 & 154 \\
\hline
\end{tabular}

magazine for $15 \mathrm{~min}$. The number of responses emitted during this period, by successive 5-min. intervals, was 52,38 , and 24 . At the conclusion of this test period each of the S's next 7 responses were followed by the light and clicker. The $\mathrm{S}^{\mathrm{D}} \mathrm{s}$ were then made contingent upon further responses on a variable ratio basis (average ratio 1:3). The responses so reinforced were also tabulated for three successive 5-min. intervals, with the results of 78,81 , and 53 responses for the three periods. It will be noted that while continuing extinction would be expected to further reduce response rate in the second $15-\min$. period, an $86 \%$ increase in response rate is realized when the light and clicker are presented as contingent stimuli. The effectiveness of the light and clicker when presented on an intermittent schedule, suggests that these stimuli did not serve simply as $\mathrm{S}^{\mathrm{D}} \mathrm{S}$ for a previously learned response (Beck, 1961). Also, it is clear that the extent of the reinforcing effectiveness observed does not allow for an explanation based upon momentary facilitation stemming from the introduction of novel stimulation during extinction.

There would appear to be no question but that $\mathrm{S}^{\mathrm{D}_{\mathrm{S}}}$ established in situations in which reinforcement has derived from the removal of negatively reinforcing stimuli function as conditioned reinforcers, even when these stimuli have no intrinsic power to reinforce. Whether these stimuli differ in any way in their systematic effect from $\mathrm{S}^{\mathrm{D}} \mathrm{s}$ established in appetitive situations, is an empirical matter deserving of further research.

\section{References}

Beck, R. C. On secondary reinforcement and shock termination. Psychol. Bull., 1961, 58, 28-45.

Dinsmoor, J. A., \& Clayton, Marilyn H. Chaining and secondary reinforcement based on escape from shock. J. exp. Anal. Behav., $1963,6,75-80$.

Wenrich, W. W., \& Cahoon, D. D. Note on secondary reinforcement using a discriminative stimulus from an aversive situation. Psychol. Rep., in press.

Note

1. This experiment was supported by NIMH Grant No. MH 08809-01. 